\title{
ZIDOVUDINE: STRUCTURAL MODIFICATIONS AND THEIR IMPACT ON BIOLOGICAL ACTIVITIES AND PHARMACOKINETIC PROPERTIES
}

\author{
NOOR UL AMIN MOHSIN ${ }^{*}, 1$, MATLOOB AHMED ${ }^{2}$ AND MUHAMMAD IRFAN ${ }^{3}$ \\ ${ }^{1}$ Department of Pharmaceutical Chemistry, Faculty of Pharmaceutical Sciences, Government College University Faisalabad, \\ Pakistan, 38000 . \\ ${ }^{2}$ Department of Chemistry, GC University Faisalabad, Pakistan, 38000. \\ ${ }^{3}$ Department of Pharmaceutics, Faculty of Pharmaceutical Sciences, Government College University Faisalabad, Pakistan, 38000.
}

\begin{abstract}
Zidovudine was the first drug approved for the treatment of Acquired Immuno Deficiency Syndrome (AIDS). Its chemical name is azidothymidine (AZT). AZT use is associated with bone marrow toxicity. Shorter half-life and inability to penetrate the blood-brain barrier are the pharmacokinetic problems of this important drug molecule. Various modifications have been carried out in the structure of AZT. These include modification of hydroxyl and azido group, thymidine ring, preparation of phosphate and phosphonate derivatives, attachment of polymers and synthesis of hybrid molecules. Some of these changes produced compounds with significantly increased activity and less toxicity. This review highlights the various structural modifications of AZT and their influence on biological activities and pharmacokinetic properties.
\end{abstract}

Keywords: Human Immunodeficiency Virus (HIV), Hybrids, Phosphate and phosphonate, Polymers, Prodrugs.

\section{INTRODUCTION}

Acquired Immuno Deficiency Syndrome (AIDS) is caused by infection from human immunodeficiency virus (HIV). It is now considered a chronic rather than acute disease [1]. HIV/AIDS is present across the world and according to the estimate of 2016, 36.7 million people are suffering from this disease. In the same year, one million deaths were reported due to this disease [2-4]. Nucleoside reverse transcriptase inhibitors are the most efficient and frequently used agents for the treatment of AIDS [5]. Azidothymidine (AZT) is still the most important drug in spite of the development of other anti-HIV agents. AZT has also been used for the treatment of colon and breast cancers and it is also effective against hepatitis [6-8]. AZT is a synthetic analogue of natural nucleoside thymidine. It is used alone or in combination with other drugs for the treatment of HIV infection. Combination therapy involves the simultaneous administration of nucleoside and non-nucleoside reverse transcriptase and protease inhibitors in order to reduce the emergence of resistant strains $[9,10]$. AZT is also an important agent in the highly active antiretroviral therapy [HAART] [11]. Treatment with AZT decreases the mortality rate and frequency of opportunistic infections in AIDS patients. AZT causes certain adverse effects such as bone marrow toxicity leading to anaemia and leukopenia which forces dose reduction and even suspension of treatment [12]. Mania, psychosis, myopathy and cardiopathy are the central nervous system (CNS) adverse effects which result after prolong use of AZT $[13,14]$. Shorter half-life and drug resistance are the other problems which demand that the drug should be administered frequently [15,16]. AZT has also poor ability to cross the blood-brain barrier (BBB) and to reach the CNS [17]. Various derivatives of this drug have been prepared to overcome these problems $[18,19]$. Structural modifications of AZT have been performed at 5'-hydroxyl group and azido group. Other changes include preparation of phosphate and phosphonate derivatives, hybridization with other active drugs and attachment of chemical delivery system. In this review, we summarized these modifications in the structure of AZT and their effects on biological activities and pharmacokinetic properties.

\section{CHEMISTRY AND BIOLOGICAL ACTIVITY}

AZT is a synthetic dideoxynucleoside in which azido group is present in place of 3'- hydroxyl group of thymidine (Figure 1). Derivatives of AZT have been described in the following sections.

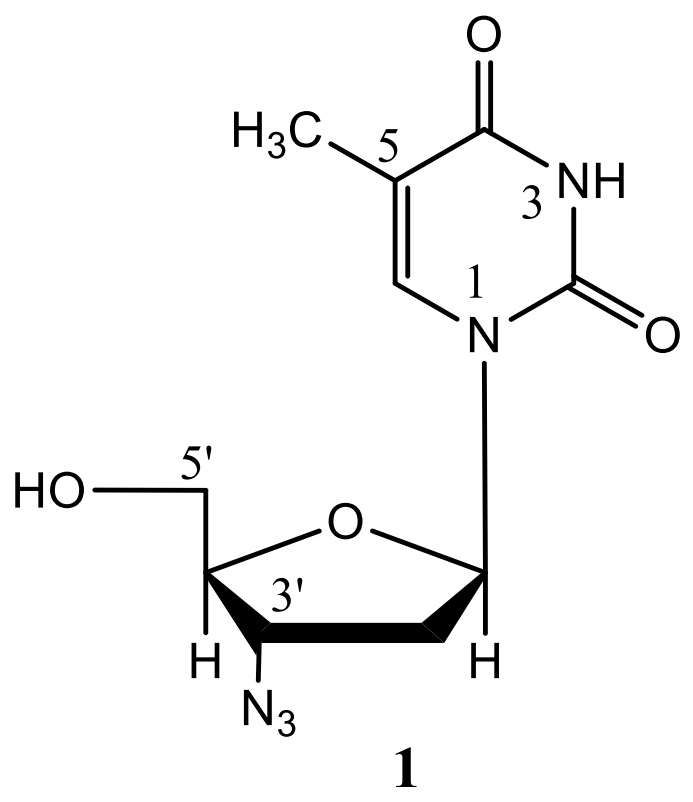

Figure 1. Structural formula of Azidothymidine. 


\subsection{Modifications at 5'-hydroxyl group}

Many derivatives of AZT have been prepared by modification of hydroxyl group at position 5'. Solyev et al. synthesized 5'-O-carbamate prodrugs of AZT and their anti-HIV activity was tested in cell culture infected with HIV-I ${ }_{899 \mathrm{~A}}$. These compounds showed moderate activity and less toxicity $\left(\mathrm{CC}_{50}>6000 \mu \mathrm{M}\right)$. Compound 2 (Figure 2) was most potent $\left(\mathrm{EC}_{50}=3.2 \mu \mathrm{M}\right)$ derivative having a free amino group attached with the carbonyl group. All derivative were chemically stable $\left(\mathrm{T}_{1 / 2}>24\right)$ and compound 3 generated the active drug slowly $\left(\mathrm{T}_{1 / 2}=8 \mathrm{hr}\right)$ as compared to the other derivatives [20]. The problem of oral bioavailability and toxicity of AZT can be minimized by using the dipeptide ester prodrugs of AZT. Santos et al. synthesized 5'-O-dipeptide ester prodrugs of AZT as a substrate for human intestinal oligopeptide transporter (HPEPT). These compounds were evaluated for their stability in human plasma and buffer of $\mathrm{pH}$ 7.4. Compound 4 showed chemical stability and good affinity $\left(\mathrm{IC}_{50}=0.15 \pm 0.01\right.$ $\mathrm{mM}$ ) for HPEPT as well as increased selectivity index. It contains side chain comprising valine and alanine amino acids. Compound $\mathbf{4}$ presented activity against HIV-1 $\left(\mathrm{IC}_{50}=1.8 \mathrm{nM}\right)$ and HIV-2 $\left(\mathrm{IC}_{50}=3.2 \mathrm{nM}\right)$ and showed less toxicity $\left(\mathrm{CC}_{50}=19.6 \mu \mathrm{M}\right)$ as compared to AZT [21]. Pemmaraju et al. attached dicarboxylic fatty acids of variable chain lengths in order to increase their lipophilicity and hence the cellular uptake. The 5 '- $O$-suberate derivative of AZT (compound 5) was found to be most potent $\left(\mathrm{EC}_{50}=0.10 \mathrm{nM}\right)$ in this series as evaluated in human peripheral blood mononuclear cells (PBMC). Compound $\mathbf{5}$ demonstrated prominent activity as compared to AZT and was also found to be less toxic $\left(\mathrm{TC}_{50}>500 \mathrm{nM}\right)$ [22]. Al Masoudi et al. synthesized 5'-alkyl sulfonate derivatives of AZT. Compound $\mathbf{6}$ showed activity against HIV-1 $\left(\mathrm{IC}_{50}=0.83\right.$ $\mu \mathrm{g} / \mathrm{ml})$ and HIV-2 $\left(\mathrm{IC}_{50}=0.93 \mu \mathrm{g} / \mathrm{ml}\right)$ and it contains 5'-thioethyl side chain. Compound $\mathbf{6}$ was also found to be cytoprotective with better selectivity index. Compound 7, a thiopropionic acid derivative also exhibited better activity against HIV-I $\left(\mathrm{IC}_{50}=0.31\right)$ and HIV-2 $(0.29 \mu \mathrm{g} / \mathrm{ml})$ as well as cytoprotectivity $\left(\mathrm{CC}_{50}=\right.$ $125 \mu \mathrm{g} / \mathrm{ml})[23]$.

$$
\begin{aligned}
& \mathbf{R}= \\
& \mathrm{H}_{3} \mathrm{C}-\mathrm{H}_{2}-\mathrm{S}-
\end{aligned}
$$$$
6
$$

$\mathbf{R}=$

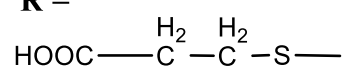

$\mathbf{R}=$
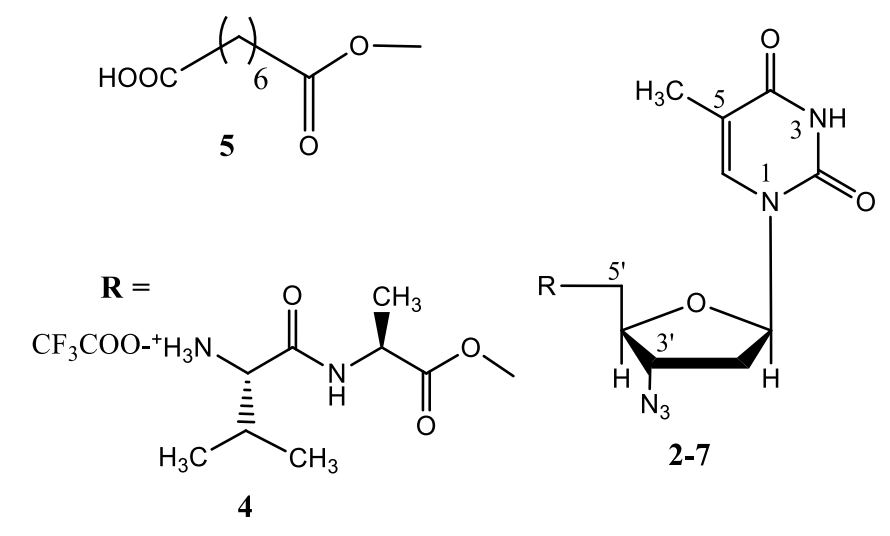

7<smiles>[R]=C(N)OC</smiles>

Figure 2. 5' hydroxyl group modified derivatives of AZT

You et al. also carried out the synthesis of AZT conjugates with cholanic acid, 2-imidazolidone-4-carboxylic acid and $\mathrm{N}, \mathrm{N}^{\prime}$-disubstituted 5-hydroxytetrahydropyrimidines-2-ones. Compound 8 (Figure 3) showed excellent activity having an $\mathrm{EC}_{50}$ value of $1.0^{\times} 10^{-7} \mathrm{M}$. Compound 9 also demonstrated prominent activity $\left(\mathrm{EC}_{50}=1.6^{\times} 10^{-8} \mathrm{M}\right)$ and good therapeutic index $\left(5.6^{\times} 10^{4} \mathrm{M}\right)$ [24]. Ursodeoxycholic acid is a bile acid which has the neuroprotective ability and can penetrate into CNS [25]. Dalpiaz et al. synthesized attached AZT to the ursodeoxycholic acid (UDCA) by an ester linkage. Compound 10 was found to be stable in phosphate buffer and hydrolysed in plasma $\left(\mathrm{t}_{1 / 2}=7.53 \mathrm{~h}\right)$ and whole blood $\left(\mathrm{t}_{1 / 2}=3.71 \mathrm{~h}\right)$ showing a controlled release of AZT. AZT alone showed lower influx permeation as compared to efflux permeation, while the influx and efflux permeations of AZT-UDCA were found to be equal. Therefore it has the ability to reach CNS and UDCA was found to be a useful compound for designing the new prodrug of AZT [26].

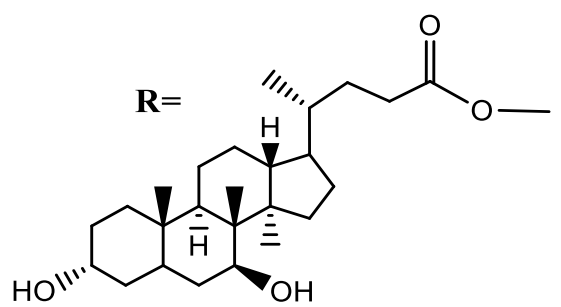

10

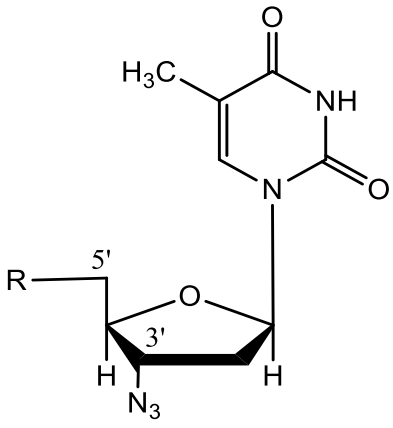

8-10<smiles></smiles>

$\mathbf{R}=$<smiles>COC(=O)CCC(=O)OC1CN(c2ccccc2)C(=O)N(c2ccccc2)C1</smiles>

Figure 3. $5^{\prime}$ hydroxyl group modified derivatives of AZT 
Da Rosa et al. synthesized 5'-aryl chalcogenium-3-amino thymidine derivatives as antitumour and antioxidant agents. Compound 11 (Figure 4) significantly inhibited the tumour growth showing more than $50 \%$ cell growth inhibition and presented the $\mathrm{IC}_{50}$ value of $6.61 \pm 2.02 \mu \mathrm{M}$ in $24 \mathrm{hr}$ of treatment. The compound contains Tellurium (Te) in its structure and showed more activity as compared to sulphur and selenium analogues. This compound also showed

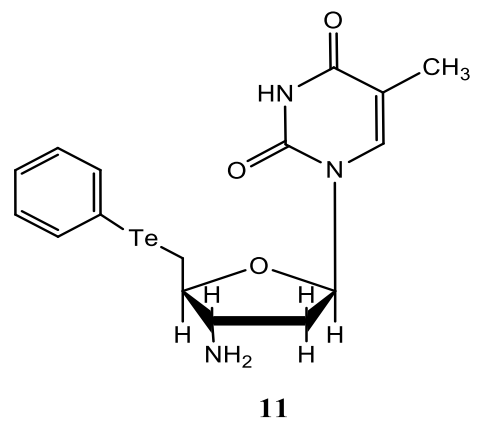

Figure 4. $5^{\prime}$ modified derivatives of AZT

\subsection{Phosphate and phosphonate derivatives of azidothymidine}

Preparation of phosphate and phosphonate derivatives is important because Nikavir, a new anti-HIV drug, is a phosphonate derivative of AZT. Villard et al. synthesized phenyl-S-acyl-2-thioethyl (SATE) phosphate esters derivatives of AZT in which one or two hydroxyl groups and the amino group were introduced on the $S$-pivaloyl-2-thioethyl group. Compound 13 (Figure 5) presented prominent activity having an $\mathrm{EC}_{50}$ value of $0.004 \mu \mathrm{M}$. Compound $\mathbf{1 4}$ displayed activity $\left(\mathrm{EC}_{50}=0.45 \mu \mathrm{M}\right)$ in thymidine kinase-deficient cells and also showed good selectivity. Stability studies indicated that compounds which contain polar hydroxyl groups are more stable to esterase hydrolysis than original compound [29]. Depot forms of various anti-HIV drugs have been developed and some of them were approved as new drugs [30]. Khandazhinskaya et al. synthesized depot forms of AZT and these compounds showed less toxicity $\left(\mathrm{CD}_{50}=260 \mu \mathrm{M}\right.$ for most toxic compound) than AZT. The active nucleoside released were AZT (25\%) and AZT-5'-phosphate (55\%). Compound 15 was the most effective compound which delivered AZT and it was having a free amino group. Pharmacokinetic data showed that aminocarbonyl phosphonate is an effective significant activity $\left(\mathrm{IC}_{50}=4.67 \pm 0.33 \mu \mathrm{M}\right)$ in lipid peroxidation assay [27]. Raviolo et al. synthesized 5'-O-carbamates, 5'-O-tosyl and tricyclic derivatives of AZT. These compounds showed less toxicity as compared to AZT but most of the compounds were also less active $\left(\mathrm{IC}_{50}=10 \mu \mathrm{mol} /\right.$ litre $)$ against HIV. Compound 12, AZT-cyclothymidine was the most potent agent in this series with an $\mathrm{IC}_{50}$ value of $1 \mu \mathrm{mol} / \mathrm{litre}[28]$.

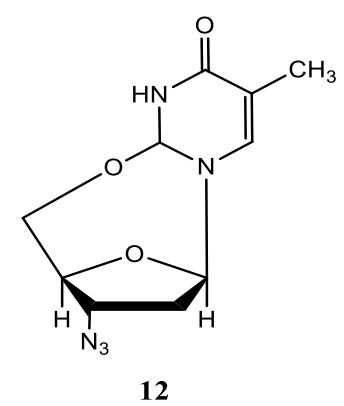

depot form at the dose of 50 and $20 \mathrm{mg} / \mathrm{kg}$ body weight [31]. Manda et al. synthesized new phosphorylated analogues of AZT and evaluated the anticancer activity against MCF-7 breast cancer cell lines by using MTT and trypan blue assay. Compounds 16-18 exhibited anticancer activities and can be considered lead molecule for further modifications [32]. Reddy et al. synthesized new phosphorylated derivatives of AZT as antimicrobial agents. Prominent activity was also observed for various compounds related to the presence of different groups at phosphorus. Compound $\mathbf{1 9}$ showed prominent antibacterial activity (zone of inhibition $=14 \mathrm{~mm}$ ). Prominent antifungal activity (zone of inhibition = 8-14 mm) was also observed for various compounds in this series [33]. Kolodziej et al. synthesized 2', 3'-dideoxynucleoside ( $N$-heteroaryl) phosphoramidate derivatives and evaluated their anti-HIV activity. AZT derivatives exhibited activity in nanomolar concentrations. Compound 20 presented prominent activity with an $\mathrm{EC}_{50}$ value of $1.1 \mathrm{nM}$ and $\mathrm{EC}_{90}$ value of $8 \mathrm{nM}$ [34]. Agarwal et al. synthesized lipophilic phosphotriester derivatives of AZT and FLT ( 3 '-fluoro-2', 3'-dideoxythymidine) by introducing long chains. Compound 21, the new triester derivative of $\mathrm{AZT}$ was found to be inactive having an $\mathrm{IC}_{50}$ value of $100 \mu \mathrm{M}$ [35].

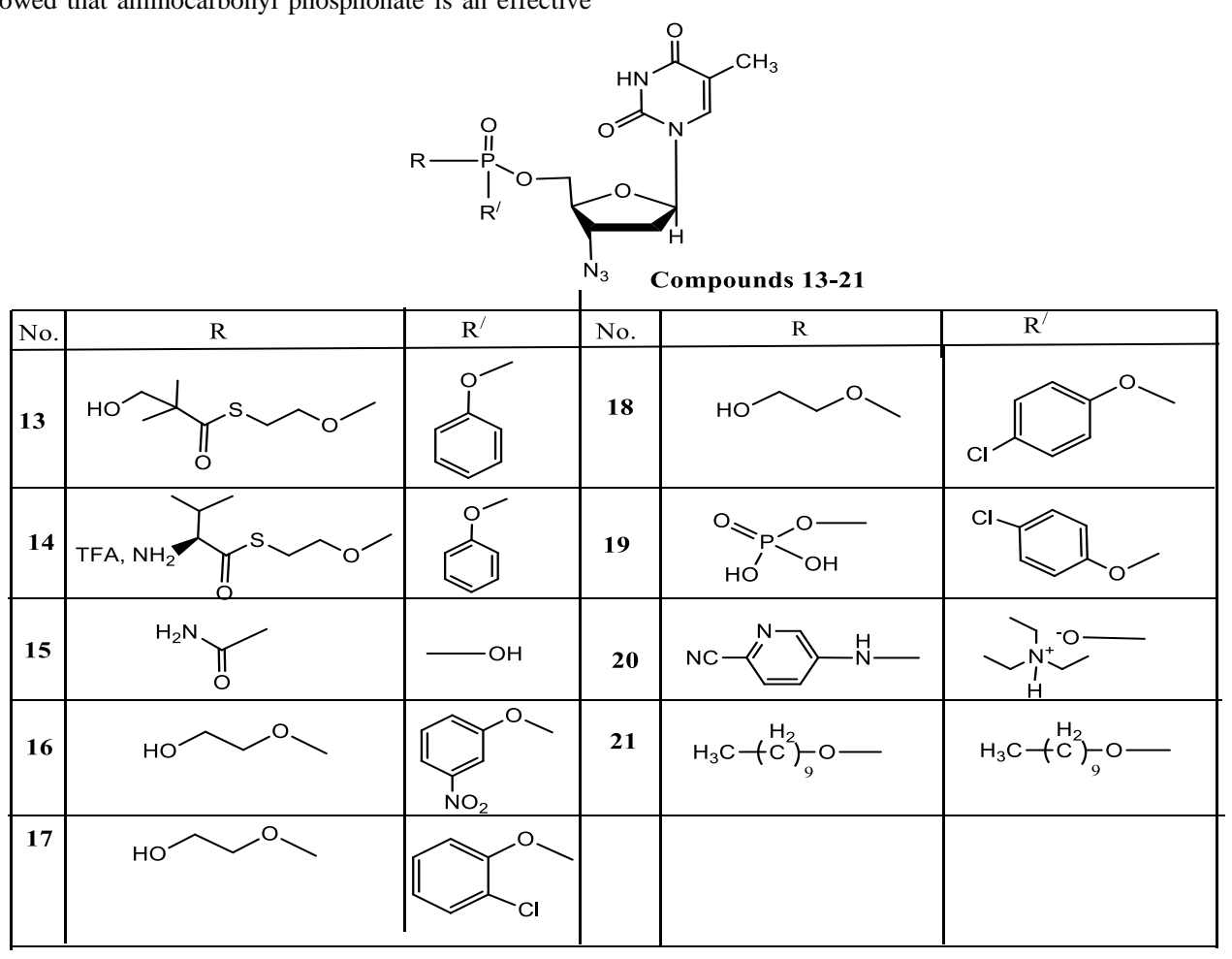

Figure 5. Phosphate and phosphonate derivatives of AZT 


\subsection{Modifications at azido group}

Azido group has been converted into triazole ring and resultant compounds exhibited anticancer activities in addition to antiviral activities. Lewandowski et al. covalently conjugated AZT derivatives to SBA-15 mesoporous silica. Two compounds were prepared by reaction of AZT with propargylamine and propargyl alcohol derivatives of (3-isocyanatopropyl) triethoxysilane. Both these compounds were immobilized on SBA-15 silica alone or together with the folic acid using grafting technique. This organic-inorganic hybrid was evaluated for its cytotoxicity against Hela and $\mathrm{Kb}$ cell lines. Compound 22 (Figure 6), the oxy derivative was found to be more toxic ( $\mathrm{IC}_{50}=3.12 \mu \mathrm{g} / \mathrm{ml}$ for $\mathrm{KB}$ cell line) as compared to the aza derivative in different cell lines [36]. Designed multiple ligands is a technique in which different drug molecules are conjugated in the same molecule [37]. Manyeruke et al. attached AZT with 3-hydroxy-3-phenyl propanoate esters and they were evaluated for their combined potential as reverse transcriptase (RT) and integrase (IN) inhibitors. Compounds $\mathbf{2 3}$ and $\mathbf{2 4}$ showed a simultaneous inhibition of RT ( $73.7 \%$ for both compounds) and IN (42.2\% and $72.2 \%$ for $\mathbf{2 3}$ and $\mathbf{2 4}$ respectively) enzymes. These compounds were found to be cytoprotective with $56.4 \%$ cell viability for most toxic compound) [38]. The importance of click chemistry in drug synthesis is that it leads to the production of new compounds under very mild conditions [39]. Sirivolu et al. converted azido group into triazole ring by using the click chemistry techniques and various aromatic rings were introduced at the position \# 4 and \# 5 of triazole ring. These derivatives showed low to moderate anti-HIV activity. Bulky aromatic ring and the substitution on position \# 5 of triazole ring was important because the compound 25 showed excellent activity $\left(\mathrm{EC}_{50}=0.067 \mu \mathrm{M}\right)$ having naphthalene ring at this position [40]. Rao et al. synthesized iminophosphorane derivatives of AZT by introducing various bioactive groups at the phosphorous atom. The antioxidant activity was evaluated by DPPH (2,2-dipheyl-1-picrylhydrazyl) assay and nitric oxide scavenging assay. Prominent activity was observed for these compounds as compared to AZT and compound $\mathbf{2 6}$ was found to be most active (Percentage of DPPH scavenging activity $=81.61 \pm 1.25 \% \mu \mathrm{g} / \mathrm{ml}$ ) antioxidant in this series [41]. Baraniak et al. also used click chemistry technique to prepare novel cinchona alkaloid and nucleoside conjugates. Compounds 27 $\left(\mathrm{ED}_{50}=1.3 \mu \mathrm{g} / \mathrm{ml}\right)$ and $28\left(\mathrm{ED}_{50}=2.1\right.$ and $3.9 \mu \mathrm{g} / \mathrm{ml}$ for both isomers) exhibited prominent cytotoxicities in human KB tumour tissue culture [42]. Olomola et al. synthesized n-benzylated coumarin-AZT conjugates and evaluated their activity as HIV-RT and protease (PR) inhibitors. These derivatives exhibited better HIV$\mathrm{RT}$ inhibitory activity with $\mathrm{IC}_{50}$ values ranging from $2.86-4.24 \mu \mathrm{M}$. Compound 29 was most potent having an $\mathrm{IC}_{50}$ value of $2.86 \mu \mathrm{M}$. These compounds showed less inhibition of $\mathrm{PR}$ enzyme with $\mathrm{IC}_{50}$ values ranging from $22.76-35.06 \mu \mathrm{M}$ [43].

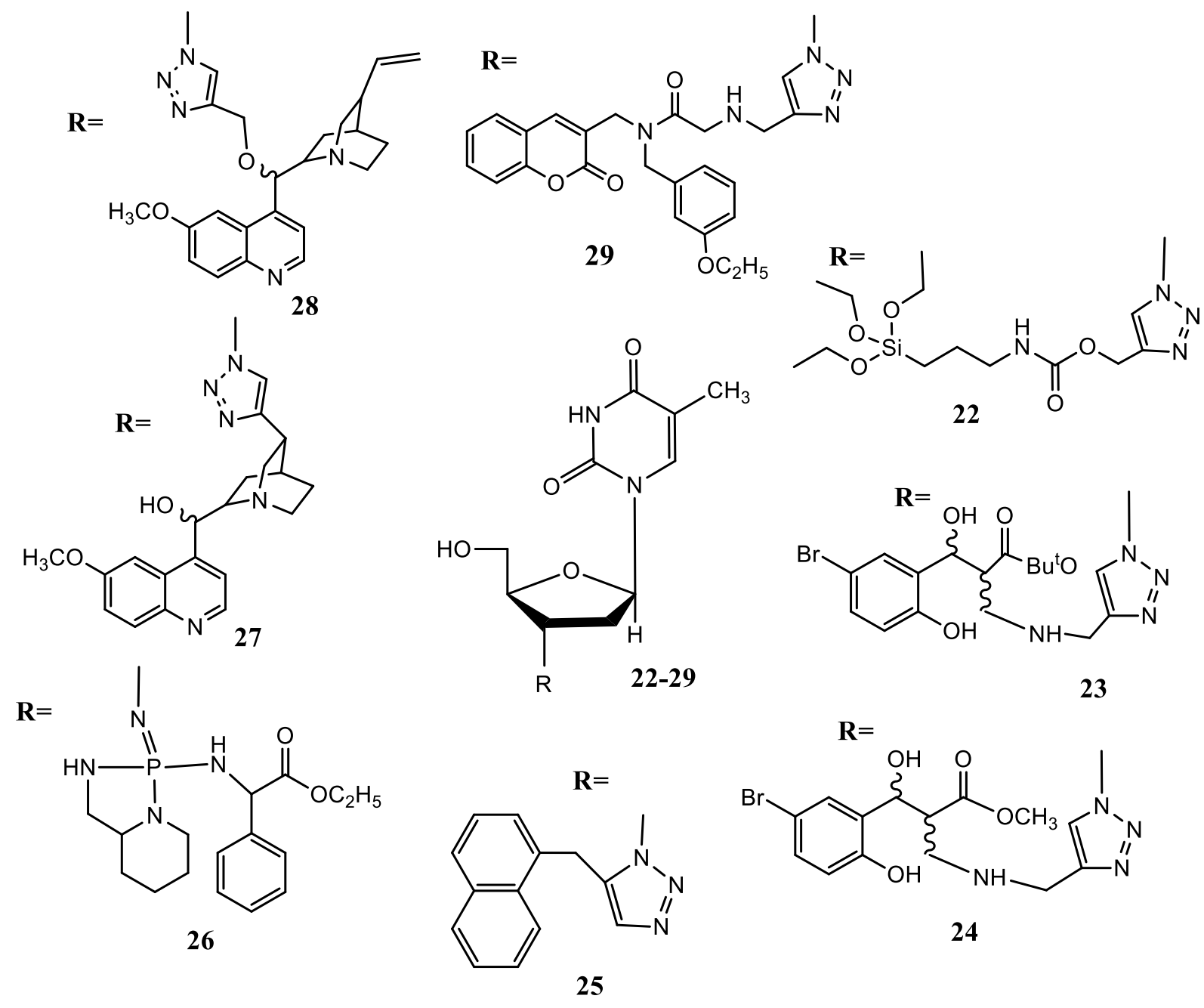

Figure 6. Azido group and furanose modified derivatives of AZT

Thi et al. attached AZT with different triterpenoid acids through the triazole amide linkage. Anticancer activities were evaluated on KB and Hep-G2 tumour cell lines. Four compounds 30- 33 (Figure 7) showed excellent anticancer activities against these two cell lines having $\mathrm{IC}_{50}$ values less than $10 \mu \mathrm{M}$. Compound 32 showed $\mathrm{IC}_{50}$ less than $5 \mu \mathrm{M}$ against both cell lines. Replacement of oxygen by nitrogen in these compound produced less active compounds [44].
Thi et al. also synthesized hybrid molecules of AZT with triterpenoid by using triazole as the linker group. These derivatives demonstrated in vitro anticancer activities against HepG2 and $\mathrm{KB}$ tumour cell lines. Compound $\mathbf{3 4}$ was most active having $\mathrm{IC}_{50}$ values of 5.9 and $7.0 \mu \mathrm{M}$ against $\mathrm{KB}$ and $\mathrm{HeP}-\mathrm{G} 2$ cell lines respectively [45]. 

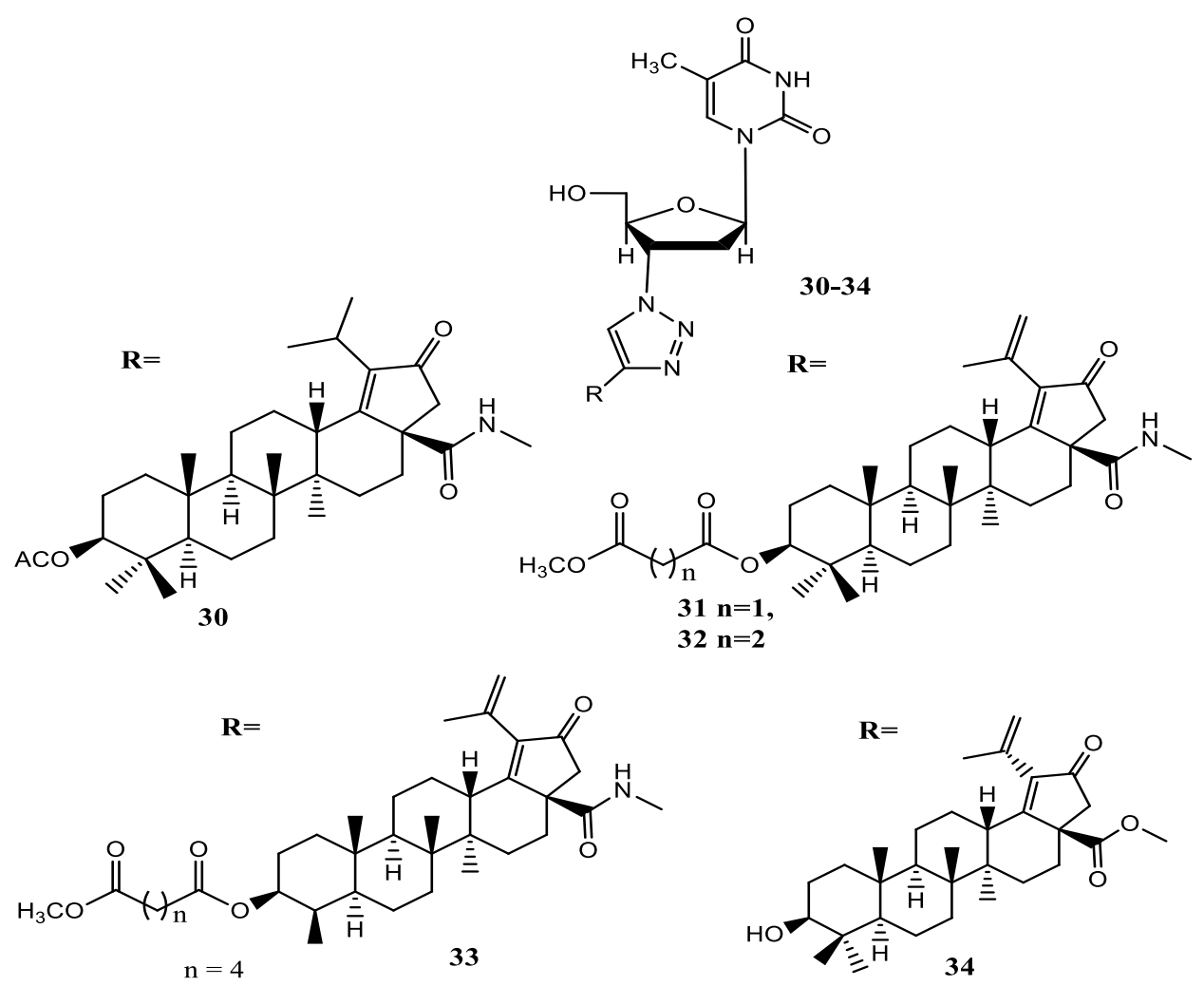

Figure 7. Derivatives of AZT with modification at azido group

\subsection{Modifications of thymine ring}

Thymine ring of AZT has been modified to produce the purine derivatives. Zhang et al. reported that L-3'-azido-2',3'-dideoxypurine nucleosides analogues displayed very weak or no antiviral activity against HIV-I and hepatitis B virus. The most potent compound in this series was converted into phosphoramidate prodrug. Compound 35 (Figure 8) exhibited anti HIV activity $\left(\mathrm{EC}_{50}=1.4 \mu \mathrm{M}\right)$ and no toxicity till $100 \mu \mathrm{M}$ [46]. 3'-Azido-2', 3'-dideoxyguanosine (ddG) has some anti-HIV activity and it serves as a lead compound for molecular modification [47]. Herman et al. synthesized 6-modified-3'-azido-ddGTP nucleotide and evaluated them for their ability to inhibit drug-resistant HIV-1 reverse transcriptase. They mimicked the adenosine which was used for DNA synthesis by HIV-I reverse transcriptase. Compound $\mathbf{3 6}$ was the most potent $\left(\mathrm{IC}_{50}\right.$ $=0.05 \mu \mathrm{M}$ ) which is $3^{\prime}$-azido-2, 6-diamino purine triphosphate derivative. Modifications at position \# 6 with branched side chain or with electronic incompatible groups alter the alignment and inhibit nucleotide incorporation [48]. Zhang et al. reported that purine modified nucleosides 3'-azido-2', 3'dideoxypurine nucleosides displayed anti-HIV activity in PBM cells and showed selectivity. Compounds $\mathbf{3 7}$ and $\mathbf{3 8}$ were most prominent with $\mathrm{EC}_{50}$ value of 0.5 $\mu \mathrm{M}$ and $0.4 \mu \mathrm{M}$ respectively. Compound $\mathbf{3 7}$ was also found to be cytoprotective $\left(\mathrm{IC}_{50}>100 \mu \mathrm{M}\right)$ against VERO and CEM cell lines [49].<smiles>CCOC(=O)[C@H](C)NP(=O)(O)OC[C@H](N)O[C@H]1C[C@@H](n2cnc3c(N)ncnc32)[C@H]1O</smiles><smiles></smiles><smiles>C=CCNc1nc(N)nc2c1ncn2[C@H]1C[C@@H](CO)[C@@H](N)O1</smiles><smiles>C=CCN(C)c1nc(N)nc2c1ncn2[C@H]1C[C@@H](N)[C@H](CO)O1</smiles>

Figure 8. AZT derivatives with modification of thymine ring 


\subsection{Conjugation of azidothymidine with polymers}

Polymers are used to control the release of the drug, increase drug solubility and sustain the drug actions [50]. N'Da et al. reported that methoxy polyethylene glycol carbonate prodrugs of AZT showed increased penetration through the skin. Compounds 39 and $\mathbf{4 0}$ (Figure 9) were more prominent and increased the penetration of AZT through the skin by $2.75-6.25$ and $2.39-10.08$ times respectively. They were also found to be stable in a phosphate buffer solution of $\mathrm{pH} 5.0$ and 7.4 but increased half-life was observed at pH of 5.0 [51]. N'Da et al. evaluated methoxy ethylene glycol carbonates of AZT for in vitro transdermal penetration through the excised human skin. Methoxy polyethylene glycol increased the penetration of AZT and compound $\mathbf{4 1}$ exhibited an increased penetration of $122.5 \mathrm{nmol} / \mathrm{cm}^{2} / \mathrm{h}$. The compound having three ethylene glycol units showed better activity in this series [52]. Neeraj et al. synthesized a prodrug of AZT by coupling it with 2-hydroxyethyl methacrylate (HEMA) through a succinic acid spacer and then polymerized this conjugate. The hydrolytic stability studies were evaluated in simulated gastric $(\mathrm{pH}=1.2)$ and intestinal fluids $(\mathrm{pH}$ $=7.4$ ). Compound $\mathbf{4 2}$ showed a sustained release from this polymeric form and amount of drug release was higher at $\mathrm{pH}$ of 7.4 .

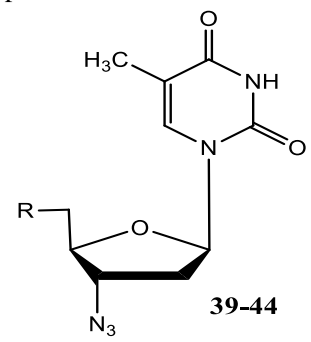<smiles>[R]OCCOC(=O)CCC(=O)OC</smiles><smiles>[R]OCCCOCCOC(=O)CCC(=O)OC</smiles>

In vivo studies of this conjugate also showed a sustained release over the period of 24 hours. Thus pharmacokinetic properties of AZT can be improved by this modification [53]. Li et al carried out the design and synthesis of polyethylene glycol conjugate of AZT as a sustained release prodrug. Succinate diester was used as a linker group. During in vitro evaluation, compound $\mathbf{4 3}$ showed a slow release of AZT in simulated gastric and intestinal fluid as compared to parent drug AZT. The in vivo evaluation showed increased half-life of this combination as well as sustained release. A prominent anti HIV activity was observed against HIV-1 $\left(\mathrm{EC}_{50}=0.0634 \mu \mathrm{M}\right)$ and HIV-2 $\left(\mathrm{EC}_{50}=0.0114 \mu \mathrm{M}\right)$ strains associated with decrease toxicity $\left(\mathrm{CC}_{50}>52.81 \mu \mathrm{M}\right)$ [54]. Li et al conjugated methoxy polyethylene glycol (mPEG) in different molecular masses such as $750 \mathrm{D}, 2,5$, $10 \mathrm{kDa}$ with succinyl-5'-O-zidovudine. These compounds showed enhanced stability and increased half-life as compared to AZT. Upon in vitro evaluation good anti-HIV activities $\left(\mathrm{IC}_{50}=0.11\right.$ to $0.35 \mu \mathrm{mol} /$ litre against HIV-I) and low toxicity $\left(\mathrm{IC}_{50}=110 \mu \mathrm{M}\right)$ were observed. Compound $\mathbf{4 4}, \mathrm{mPEG}_{750}$ was found to be most active $\left(\mathrm{IC}_{50}=0.11 \mu \mathrm{mol} / \mathrm{L}\right.$ against HIV-I) and least toxic $\left(\mathrm{IC}_{50}=110\right.$ $\mu \mathrm{mol} / \mathrm{L})$ molecule in this series. It looks an efficient method for slow and prolonged release of AZT [55].

$\mathbf{R}=$<smiles>COC(=O)OCCOCC(C)(C)OC</smiles>

$$
39 \mathrm{n}=1
$$

$40 \mathrm{n}=8$

$\mathbf{R}=$<smiles>COCCOCCOC(=O)OC</smiles>
$41 \mathrm{n}=3$<smiles></smiles>

Figure 9. Polymeric conjugates of AZT

In an attempt to overcome the problem of the shorter half-life of AZT, Wannachaiyasit et al. synthesized dextrin-AZT conjugate as a sustained release prodrug. AZT was succinoylated followed by treatment with dextrin to form the required conjugates. Compound 45 (Figure 10) was stable at $\mathrm{pH}$ of 5.5 and released drug at $\mathrm{pH}$ of 7.4. An increased plasma half-life and mean residence time were observed for this conjugate. Upon in vivo evaluation after $\mathrm{I} / \mathrm{V}$ administration sustained release of drug in about $30 \mathrm{hrs}$ was observed [56]. In another study, Senanayake et al conjugated AZT with polyethylene glycol (PEG) cholesteryl- $\varepsilon$-polylysine (CEPL) nanogels via succinate as a linker. Compound 46 presented good pharmacokinetic properties, less toxicity and tenfold suppression of reverse transcriptase activity. The CEPL-nucleoside reverse transcriptase inhibitor (NRTI) prodrug released the nucleoside at a sustained rate and was found to be an efficient drug carrier [57].

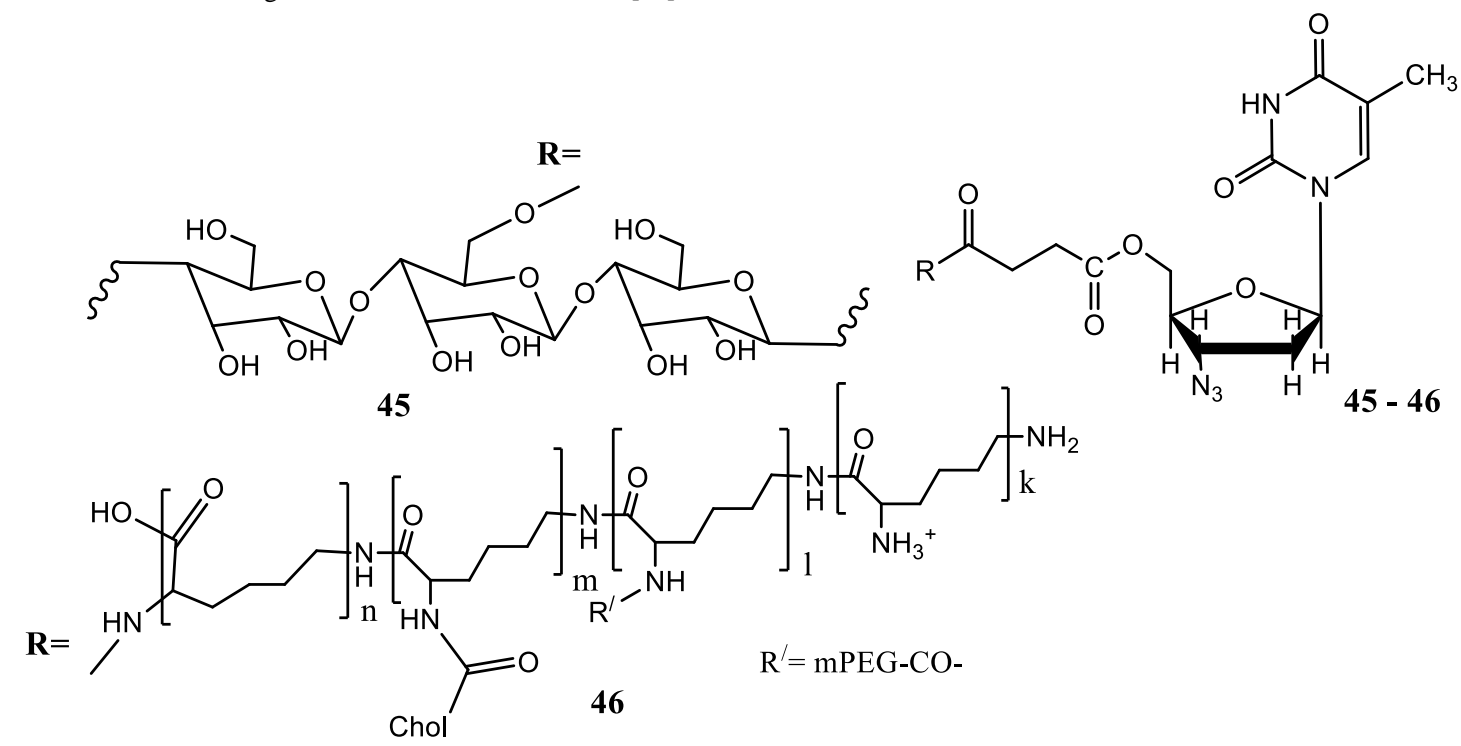

Figure 10. Polymeric conjugates of AZT 


\subsection{Combination of azidothymidine with other drug molecules}

Chemical linkage of two drugs to produce one molecule is called a duplex drug. After uptake drug is broken down to metabolites with additive or synergistic properties. Ahmadbeni et al. synthesized new symmetrical and unsymmetrical bis-(cyclosal) derivatives of AZT and fluorodeoxythymidine (FLT). These compound were found to be cytoprotective $\left(\mathrm{CC}_{50}>100 \mu \mathrm{M}\right)$ and showed moderate anti-HIV activity. Compound 47 (Figure 11) was most active $\left(\mathrm{IC}_{50}=2.8 \mu \mathrm{M}\right)$ and it contained AZT and FLT in the same molecule [58]. Sriram et al. synthesized prodrugs of AZT by esterification of 5'- $O$-hydroxyl group with antibiotics such as ciprofloxacin, norfloxacin, isoniazid and pyrazinamide. Compound 48 was the most active $\left(\mathrm{EC}_{50}=0.064 \mu \mathrm{M}\right)$ agent in this series and it was conjugate of AZT with pyrazinamide. AZT prodrugs with ciprofloxacin and norfloxacin showed excellent activity against Mycobacterium tuberculosis $(99 \%$ inhibition). This is advantageous for AIDS patients because they are highly susceptible to tuberculosis (TB) [59]. In another duplex drug approach, Schott et al. combined AZT and phosphonoformate (PFA) via octadecylglycerol backbone. Compound 49 presented higher activity $\left(\mathrm{IC}_{50}=1.18 \mu \mathrm{M}\right)$ as compared to both AZT and PFA against ganciclovir-resistant strains of HIV [60]. Senthilkumar et al. connected fluoroquinolones at 5-methyl and 5'-hydroxyl groups of AZT and evaluated their potential as anti-HIV and antimycobacterial agents. Derivatives with modification at 5-methyl group did not show prominent activity. Derivatives having fluoroquinolones at position 5 ' exhibited excellent activity against mycobacterium $\left(\mathrm{EC}_{50}=0.0018-0.037 \mu \mathrm{M}\right)$ and $\mathrm{HIV}\left(\mathrm{EC}_{50}=\right.$ $0.0012-0.033 \mu \mathrm{M})$. Compound $\mathbf{5 0}$ presented prominent anti-HIV activity having an $\mathrm{EC}_{50}$ value of $0.0012 \mu \mathrm{M}$. It was concluded that ester derivatives are hydrolyzed to generate the active drug AZT [61]. Solvey et al. reported that phosphonate dimeric molecule of AZT and a heterodimer of AZT with 2',3'dideoxy-3'-thiacytidine (3TC) demonstrated moderate anti-HIV $\left(\mathrm{EC}_{50}=0.015\right.$ $\mu \mathrm{M})$ activity in HIV-1 infected human T4-lymphoblastoid cell line. Compound 51 was found to be the most active molecule and it is a dimeric molecule of AZT. But this compound showed more toxicity $\left(\mathrm{CC}_{50}=29 \mu \mathrm{M}\right)$ as compared to AZT and less selectivity index [62]. Vanpuille et al. synthesized a heterodimeric molecule of AZT with 3-TC. Compound $\mathbf{5 2}$ was the most potent having $\mathrm{EC}_{50}$ value of $3 \mathrm{nM}$ in MT-4 cell culture as compared to the standard drug. Compound $\mathbf{5 2}$ also showed less toxicity [63].

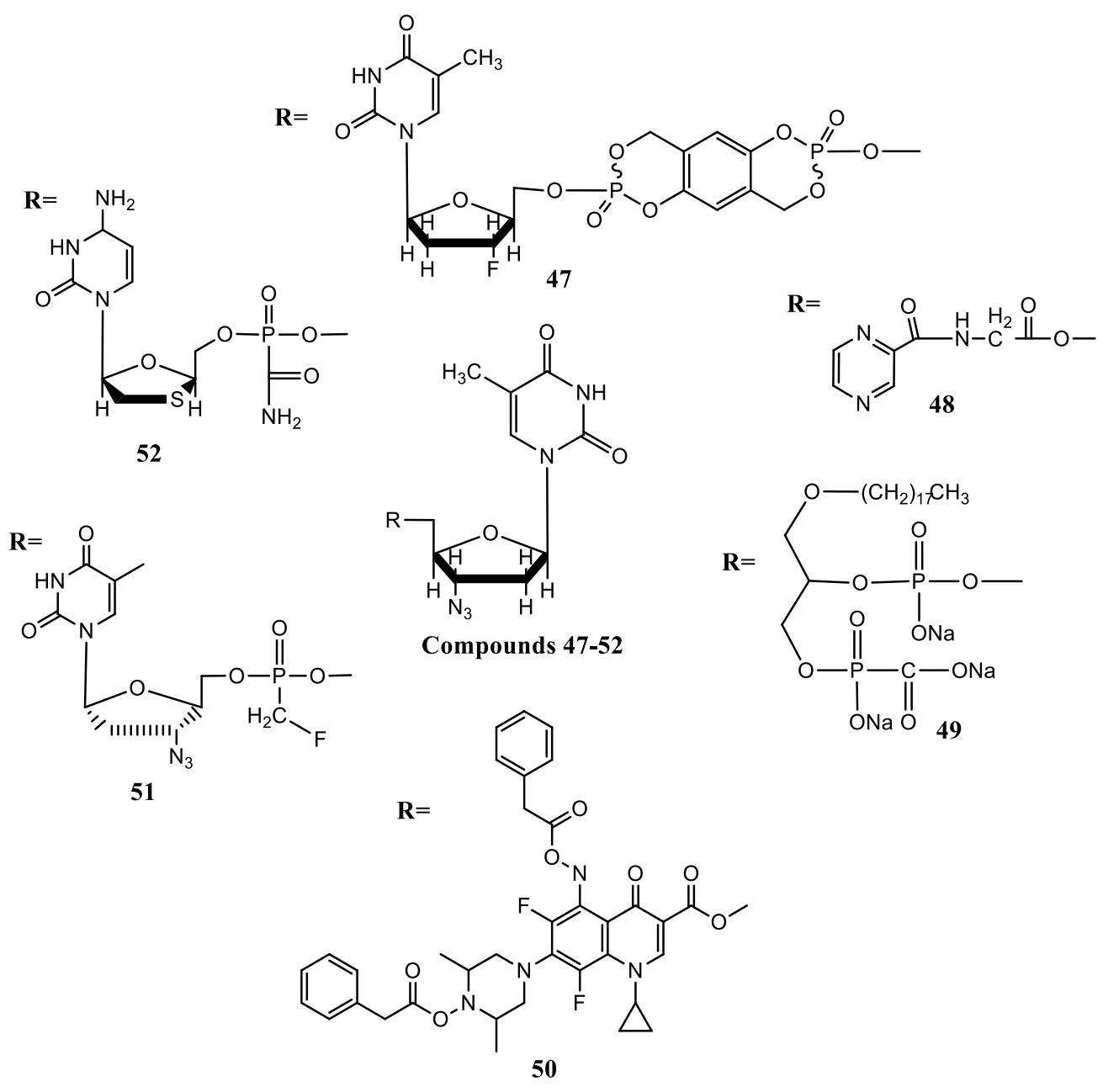

Figure 11. AZT combination with other drug molecules

\section{CONCLUSION}

A number of derivatives of AZT have been synthesized which have presented interesting biological activities. Prodrugs of AZT were prepared by modification of position 5' with amino acid, fatty acids, steroids, carbohydrates, alkyl carbonate, carbamate and thioalkyl groups. Some of these derivatives such as carbonates, carbamates and fatty acid showed less toxicity as compared to AZT. Some phosphate derivatives of AZT e.g. SATE derived compounds, showed anti-HIV activity in the thymidine kinase-deficient cell. Phosphorylated derivatives of AZT having aromatic rings in the side chain presented anticancer and antimicrobial activities. Azido group of AZT has been converted into triazole ring and triazole ring was further attached with triterpenoids, quinolines, coumarin and aromatic rings. Triterpenoids, quinoline and isocyanatopropyl triethoxysilane derivatives of AZT demonstrated anticancer activities. Derivatives of AZT having the purine ring in place of thymine ring also showed anti-HIV activity. Polymeric forms of AZT constitute PEG, methoxy PEG, PolyHEMA, dextrin, and PEG-CEPL conjugates. These derivatives exhibited increased half-life and were also found to be stable. Hybrid molecules of AZT with other antiviral and antibiotics presented vital activities. Hybrid molecular strategy with antibiotics is significant because resultant molecules showed dual activity i.e. antibacterial and antiviral and these compounds also showed a better therapeutic index. 


\section{REFERENCES}

1. B. Knoll, B. Lassmann and Z. Temesgen, Int. J. Dermatol. 46, 1219, (2007).

2. M. S. Cohen, N. Hellmann, J. A. Levy, K. DeCock and J. Lange, J. Clin. Invest. 118, 1244, (2008).

3. WHO, HIV/AIDS, (2016).

4. UNAIDS Fact sheet, (2016) www.unaids.org.

5. G. R. Kaufmann and D. A. Cooper, Curr. Opin. Microbiol. 3, 508, (2000).

6. V. V. Iyer, G. W. Griesgraber, M. R. Radmer, E. J. McIntee and C. R. Wagner, J. Med. Chem. 43, 2266, (2000).

7. S. Vyas, R. Subhedar and S. Jain, J. Pharm. Pharmacol. 58, 321, (2006).

8. D. Wu, S. Ji, Y. Wu, Y. Ju and Y. Zhao, Bioorg. Med. Chem. Lett. 17, 2983, (2007).

9. I. Kostova, S. Raleva, P. Genova and R. Argirova, Bioinorg. Chem. Appl. 2006, (2006).

10. R. Ragno, S. Frasca, F. Manetti, A. Brizzi and S. Massa, J. Med. Chem. 48, 200, (2005).

11. S. Broder, Antiviral Res. 85, 1, (2010).

12. D. D. Richman, M. A. Fischl, M. H. Grieco, M. S. Gottlieb, P. A. Volberding, O. L. Laskin, J. M. Leedom, J. E. Groopman, D. Mildvan and M. S. Hirsch, New Engl. J. Med. 317, 192, (1987).

13. M. S. Abers, W. X. Shandera and J. S. Kass, CNS Drugs 28, 131, (2014).

14. M. D. Lynx and E. E. McKee, Biochem. Pharmacol. 72, 239, (2006).

15. L. M. Mansky and L. C. Bernard, J. Virol. 74, 9532, (2000).

16. D. D. Richman, Antiviral Res. 71, 117, (2006).

17. W. M. Pardridge, Mol. Interventions 3, 90, (2003).

18. J. Im, W. Kim, K.-T. Kim and S.-K. Chung, Chem. Commun., 4669, (2009).

19. H. Song, G. W. Griesgraber, C. R. Wagner and C. L. Zimmerman, Antimicrob. Agents Chemother. 46, 1357, (2002).

20. P. N. Solyev, A. V. Shipitsin, I. L. Karpenko, D. N. Nosik, L. B. Kalnina, S. N. Kochetkov, M. K. Kukhanova and M. V. Jasko, Chem. Biol. Drug Des. 80, 947, (2012)

21. C. Santos, J. Morais, L. Gouveia, E. De Clercq, C. Pannecouque, C. U. Nielsen, B. Steffansen, R. Moreira and P. Gomes, Chem. Med. Chem. 3, 970, (2008).

22. B. Pemmaraju, H. K. Agarwal, D. Oh, K. W. Buckheit, R. W. Buckheit Jr, R. Tiwari and K. Parang, Tetrahedron Lett. 55, 1983, (2014).

23. N. A. Al-Masoudi, Y. A. Al-Soud, I. A. Ali, T. Schuppler, C. Pannecouque and E. De Clercq, Nucleos. Nucleot. Nucl. 26, 223, (2007)

24. Z. You and H. J. Lee, Nucleos. Nucleot. Nucl. 25, 37, (2006).

25. G. J. Parry, C. M. Rodrigues, M. M. Aranha, S. J. Hilbert, C. Davey, P. Kelkar, W. C. Low and C. J. Steer, Clin. Neuropharmacol. 33, 17, (2010).

26. A. Dalpiaz, G. Paganetto, B. Pavan, M. Fogagnolo, A. Medici, S. Beggiato and D. Perrone, Mol. Pharm. 9, 957, (2012).

27. R. M. da Rosa, B. C. Piccoli, F. D. A. da Silva, L. Dornelles, J. B. Rocha, M. S. Sonego, K. R. Begnini, T. Collares, F. K. Seixas and O. E. Rodrigues, Med. Chem. Comm. 8, 408, (2017).

28. M. A. Raviolo, J. S. Trinchero-Hernández, G. Turk and M. C. Briñón, J. Braz. Chem. Soc. 20, 1870, (2009)

29. A.-L. Villard, G. Coussot, I. Lefebvre, P. Augustijns, A.-M. Aubertin, G. Gosselin, S. Peyrottes and C. Périgaud, Biorg. Med. Chem. 16, 7321, (2008).

30. T. Calogeropoulou, A. Detsi, E. Lekkas and M. Koufaki, Curr. Top. Med. Chem. 3, 1467, (2003)

31. A. L. Khandazhinskaya, D. V. Yanvarev, M. V. Jasko, A. V. Shipitsin, V. A. Khalizev, S. I. Shram, Y. S. Skoblov, E. A. Shirokova and M. K. Kukhanova, Drug Metab. Dispos. 37, 494, (2009).

32. P. Manda and M. Jayapal, Heterocyclic Lett. 5, 185, (2015).

33. S. S. Reddy, V. K. Rao, K. Venkataramana, C. S. Reddy, S. Ghosh and C. N. Rju, Der Pharma Chemica 2, 1, (2010).

34. K. Kolodziej, J. Romanowska, J. Stawinski, J. Boryski, A. Dabrowska, A. Lipniacki, A. Piasek, A. Kraszewski and M. Sobkowski, Eur. J. Med. Chem. 100, 77, (2015).

35. H. K. Agarwal, G. F. Doncel and K. Parang, Tetrahedron Lett. 49, 4905, (2008).

36. D. Lewandowski, M. Lewandowska, P. Ruszkowski, A. Pińska and G. Schroeder, PLoS One 10, e0126251, (2015).

37. R. Morphy and Z. Rankovic, J. Med. Chem. 48, 6523, (2005)

38. M. H. Manyeruke, T. O. Olomola, S. Majumder, S. Abrahams, M. Isaacs, N. Mautsa, S. Mosebi, D. Mnkandhla, R. Hewer and H. C. Hoppe, Biorg. Med. Chem. 23, 7521, (2015).

39. H. C. Kolb, M. Finn and K. B. Sharpless, Angew. Chem. Int. Ed. 40, 2004, (2001).
40. V. R. Sirivolu, S. K. V. Vernekar, T. Ilina, N. S. Myshakina, M. A. Parniak and Z. Wang, J. Med. Chem. 56, 8765, (2013).

41. A. J. Rao, V. K. Rao, P. V. Rao, B. S. Krishna, C. N. Raju and S. Ghosh, Int. J. Pharma Bio Sci 1, (2010).

42. D. Baraniak, K. Kacprzak and L. Celewicz, Bioorg. Med. Chem. Lett. 21, 723, (2011).

43. T. O. Olomola, R. Klein, N. Mautsa, Y. Sayed and P. T. Kaye, Biorg. Med. Chem. 21, 1964, (2013).

44. T. A. D. Thi, N. T. K. Tuyet, H. T. Nguyen, C. B. Thi, H. T. Phuong, L. Van Boi, T. Van Nguyen and M. D'hooghe, Tetrahedron Lett. 56, 218, (2015).

45. T. A. D. Thi, N. T. K. Tuyet, H. T. Nguyen, C. B. Thi, T. D. Duy, M. D'hooghe and T. Van Nguyen, Bioorg. Med. Chem. Lett. 24, 5190, (2014).

46. H.W. Zhang, M. Detorio, B. D. Herman, S. Solomon, L. Bassit, J. H. Nettles, A. Obikhod, S.J. Tao, J. W. Mellors and N. Sluis-Cremer, Eur. J. Med. Chem. 46, 3832, (2011).

47. N. Sluis-Cremer, D. Koontz, L. Bassit, B. I. Hernandez-Santiago, M. Detorio, K. L. Rapp, F. Amblard, L. Bondada, J. Grier and S. J. Coats, Antimicrob. Agents Chemother. 53, 3715, (2009).

48. B. D. Herman, R. F. Schinazi, H.-w. Zhang, J. H. Nettles, R. Stanton, M. Detorio, A. Obikhod, U. Pradere, S. J. Coats and J. W. Mellors, Nucleic Acids Res. 40, 381, (2011).

49. H.-w. Zhang, S. J. Coats, L. Bondada, F. Amblard, M. Detorio, G. Asif, E. Fromentin, S. Solomon, A. Obikhod and T. Whitaker, Bioorg. Med. Chem. Lett. 20, 60, (2010).

50. P. Singh, U. Gupta, A. Asthana and N. K. Jain, Bioconj. Chem. 19, 2239, (2008).

51. D. D. N'da and J. C. Breytenbach, J. Pharm. Pharmacol. 61, 721, (2009).

52. D. D. David, J. C. Breytenbach and J. W. Breytenbach, Arzneimittelforschung 60, 575, (2010).

53. A. Neeraj, M. Chandrasekar, U. Sara and A. Rohini, Drug Deliv. 18, 272, (2011).

54. W. Li, Y. Chang, P. Zhan, N. Zhang, X. Liu, C. Pannecouque and E. De Clercq, Chem. Med. Chem. 5,1893, (2010).

55. W. Li, J. Wu, P. Zhan, Y. Chang, C. Pannecouque, E. De Clercq and X. Liu, Int. J. Biol. Macromol. 50, 974, (2012)

56. S. Wannachaiyasit, P. Chanvorachote and U. Nimmannit, AAPS Pharm. Sci. Tech. 9, 840, (2008).

57. T. Senanayake, S. Gorantla, E. Makarov, Y. Lu, G. Warren and S. Vinogradov, Mol. Pharm. 12, 4226, (2015).

58. Y. Ahmadibeni, R. Tiwari, C. Swepson, J. Pandhare, C. Dash, G. F. Doncel and K. Parang, Tetrahedron Lett. 52, 802, (2011).

59. D. Sriram, N. Srichakravarthy, T. Bal and P. Yogeeswari, Biomed. Pharmacother. 59, 452, (2005).

60. H. Schott, K. Hamprecht, S. Schott, T. C. Schott and R. A. Schwendener, Biorg. Med. Chem. 17, 303, (2009).

61. P. Senthilkumar, J. Long, R. Swetha, V. Shruthi, R. R. Wang, S. Preethi, P. Yogeeswari, Y.T. Zheng and D. Sriram, Nucleos. Nucleot. Nucl. 28, 89, (2009).

62. P. N. Solyev, M. V. Jasko, I. L. Karpenko, Y. A. Sharkin, A. V. Shipitsyn and M. K. Kukhanova, Nucleos. Nucleot. Nucl. 33, 64, (2014).

63. C. Vanpouille, A. Khandazhinskaya, I. Karpenko, S. Zicari, V. Barreto-deSouza, S. Frolova, L. Margolis and S. Kochetkov, Antiviral Res. 109, 125, (2014). 